\title{
Land Surface Temperature and Its Impact on Land Use and Land Cover: Long-Term Rainfall Analysis Using CHIRPS PENTAD Data in Telangana's Mahabubnagar District
}

\author{
Aloshree Choudhury, ${ }^{1, *}$, Vazeer Mahammood ${ }^{2}$, K. H. V. Durga Rao ${ }^{1}$ \\ ${ }^{1}$ National Remote Sensing Centre (NRSC), Indian Space Research Organisation (ISRO), India \\ ${ }^{2}$ Department of Civil Engineering, Andhra University, Visakhapatnam, India
}

Received September 24, 2021; Revised November 15, 2021; Accepted December 13, 2021

\section{Cite This Paper in the following Citation Styles}

(a): [1] Aloshree Choudhury, Vazeer Mahammood, K. H. V. Durga Rao, "Land Surface Temperature and Its Impact on Land Use and Land Cover: Long-Term Rainfall Analysis Using CHIRPS PENTAD Data in Telangana's Mahabubnagar District," Environment and Ecology Research, Vol. 9, No. 6, pp. 399 - 418, 2021. DOI: 10.13189/eer.2021.090607.

(b): Aloshree Choudhury, Vazeer Mahammood, K. H. V. Durga Rao (2021). Land Surface Temperature and Its Impact on Land Use and Land Cover: Long-Term Rainfall Analysis Using CHIRPS PENTAD Data in Telangana's Mahabubnagar District. Environment and Ecology Research, 9(6), 399 - 418. DOI: 10.13189/eer.2021.090607.

Copyright $\odot 2021$ by authors, all rights reserved. Authors agree that this article remains permanently open access under the terms of the Creative Commons Attribution License 4.0 International License

\begin{abstract}
Drastic changes at a global level in land use and land cover are having a negative impact on the environment, both directly and indirectly. One of the most important factors contributing to global warming is rapid urbanization, which is affected by surface temperature and water resources. One of the primary contributors to climate change and global warming is temperature. Rapid urbanization, which results in polluted water and causes other human activities in nearly every section of the country, has a significant impact on surface waterbodies. Land surface temperature can be determined using the Landsat series' thermal band. Temperatures have risen from 2005 to 2020, according to image analysis. Land surface temperature is directly affected by changes in land use and land cover. According to the report, urban areas and built-up regions should be developed in tandem with additional plantings and vegetation; this will result in keeping the temperature under control. The purpose of this research is to identify how land surface temperature changes over time, how it influences land use and land cover changes, and how it affects surface waterbodies, as turbid waterbodies have higher temperatures than clear waterbodies. The time-series change in water spread area over key waterbodies from 2005 to 2020 is also discussed in this study. Long-term rainfall analysis (1984-2014) has
\end{abstract}

also been carried out to determine how drought affected the study area during the year 2015 .

Keywords Land Use and Land Cover, Land Surface Temperature, Water Spread Area, GEE

\section{Introduction}

The deterioration of natural resources is mostly caused by changes in land use and land cover (LULC) over time as a result of increased human activity such as advanced farming methods, deforestation, and so on. One of the most major causes contributing to the rising land surface temperature (LST) is increased urbanization [1]. Increased urbanization, in turn, has an impact on surface water in terms of turbidity. Consequently, surface water quality is being deteriorated as a result of increased population and urbanization [2].

The LST reflects a picture of the physical qualities of the surface and climate, which are important in a variety of environmental processes [3]. By 2050, it is expected that around $70 \%$ of the world's population will be living in cities [4]. LULC change is a global phenomenon that is 
negatively impacting the environment and will continue to do so both directly and indirectly in different parts of the world. It has a negative impact on the availability of water. Rapid urbanization is a key cause of land-use change, which is one of the leading sources of global warming; LULC change is a major source of concern around the world [5].

For climatological and meteorological purposes, remote sensing is a useful technique [6]. Various regional and climate studies have employed satellite temperature data based on satellite imageries.

LULC are crucial in studies of regional, local, and global environmental change $[7,8]$. The way forests, marshes, impermeable surfaces, agricultural, and other types of land and water cover the Earth's surface is referred to as land cover [9]. Land use refers to how humans use the terrain for development, conservation, or a combination of the two. Recreational spaces, wildlife habitats, agricultural land, and built-up land are all examples of land use [10].

The normalized difference vegetation index (NDVI) is a combination of red and near-infrared (NIR) reflectance measurements and is one of the most widely used vegetation indices in the world. It has been used extensively for vegetation over spatiotemporal resolution [11]. Lakes and ponds connected with wetlands were identified using the normalized difference water index (NDWI) [12]. False readings from built-up land are also included in the NDWI. In Landsat images, [13] proposed modified NDWI (MNDWI), which substituted Band 4 (NIR) with Band 5, short-wave infrared (SWIR). MNDWI's threshold is more stable than that of other water indices [14]. The MNDWI can improve open water features while effectively suppressing and even eliminating built-up land, vegetation, and soil noise. The automated water extraction index (AWEI) was created to increase classification accuracy in areas that had shadows and dark surfaces, which were frequently misclassified by conventional classification approaches [15].

Landsat series data were downloaded from the USGS Earth Explorer and utilized to generate LST using the thermal band, as well as to calculate LULC. The visual interpretation technique was employed to analyze LULC.
The surface temperature was determined using the NDVI and emissivity data calculated from the thermal band. In addition, to determine the time-series change over significant waterbodies, indices and band ratioing techniques were employed to produce surface waterbodies. Consequently, this study demonstrates that these strategies can provide better answers for long-term development.

\section{Objective of the Study}

The goal of this study is to figure out what the LST is and how it affects LULC. The following are the key goals:

- From 2005 to 2020, calculate the change in LST

- LST's effect on LULC features

- Changes in major surface waterbodies throughout time, from 2012 to 2020

- Rainfall Analysis using CHIRPS PENTAD Data from 1984 to 2014 (2015 declared as drought / dry year)

\section{Study Area}

Mahabubnagar is one of Telangana's districts. Palamoor is another name for it. In honor of Nizam of Hyderabad, Mir Mahbub Ali Khan Asaf Jah VI, the name was changed to Mahabubnagar (1869-1911 AD). The district's eastern longitudes are $77^{\circ} 15^{\prime}$ and $79^{\circ} 15^{\prime} \mathrm{E}$, while its northern latitudes are $15^{\circ} 55^{\prime}$, and $17^{\circ} 20^{\prime} \mathrm{N}$. It is 498 meters above sea level on average (1,633 feet). The Mahabubnagar district receives an average annual rainfall of $728.9 \mathrm{~mm}$, ranging from 438.1 to $1,316 \mathrm{~mm}$. Figure 1 depicts the location map.

Mahabubnagar is the southernmost district of Nizam's Hyderabad state, bounded on the south by the Krishna River and on the east by the Guntur District of Andhra Pradesh. To the north lie the Kurnool District of Andhra Pradesh and the Nalgonda and Ranga Reddy districts; to the west are the Karnataka districts of Gulbarga and Raichur. The Jurala Project (Priyadarshini Jurala Project) is the district's primary irrigation project, built on the Krishna River. 


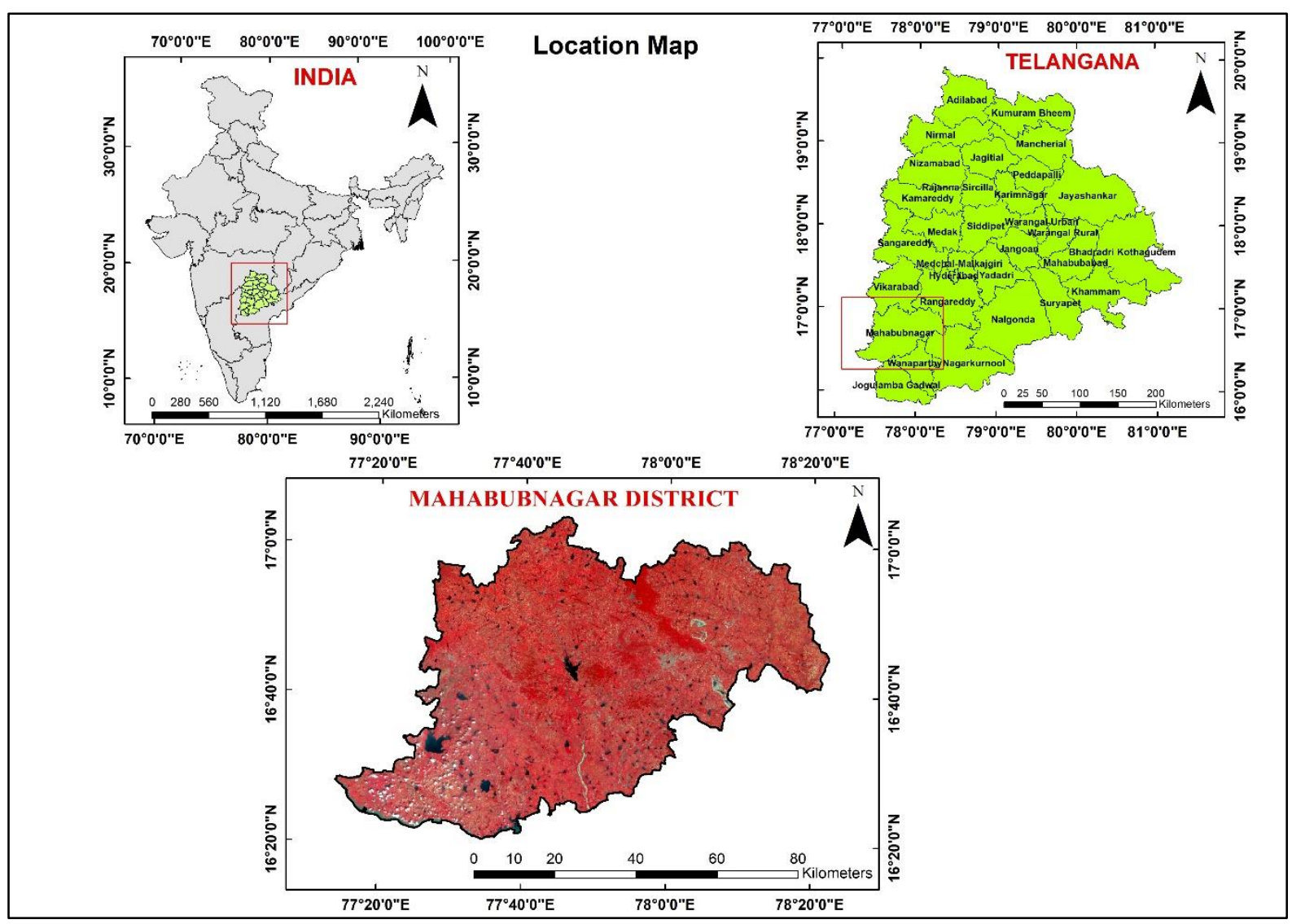

Figure 1. Location Map of the Study Area

Table 1. Data used and their description

\begin{tabular}{|c|c|c|c|}
\hline S.No. & Date \& Year & Path - Row & Satellite - Sensor \\
\hline 1. & $14^{\text {th }}$ March 2005 & $144 / 048-049$ & LANDSAT -7 ETM+ \\
\hline 2. & $17^{\text {th }}$ November 2005 & $144 / 048-049$ & LANDSAT -5 TM \\
\hline 3. & $2^{\text {nd }}$ April 2012 & $144 / 048-049$ & LANDSAT -7 ETM+ \\
\hline 4. & $14^{\text {th }}$ December 2012 & $144 / 048-049$ & LANDSAT -7 ETM+ \\
\hline 5. & $19^{\text {th }}$ April 2015 & $144 / 048-049$ & LANDSAT -8 OLI \\
\hline 6. & $21^{\text {st }}$ November 2015 & $144 / 048-049$ & LANDSAT -8 OLI \\
\hline 7. & $16^{\text {th }}$ April 2020 & $144 / 048-049$ & LANDSAT -8 OLI \\
\hline 8. & $10^{\text {th }}$ November 2020 & $144 / 048-049$ & LANDSAT -8 OLI \\
\hline
\end{tabular}

\section{Materials and Methodology}

\subsection{Materials}

Landsat data were utilized to determine the LST and LULC of Mahabubnagar District from 2005 to 2020, in order to conduct this study. Cloud free Landsat data were used for this study. Table 1 shows the specifics of the data that were used.

\subsection{Methodology}

Figure 2 depicts the overall methods used in this investigation. The purpose of this research was to examine LULC change and its effects on LST as well as time-series variations in significant surface water bodies. 


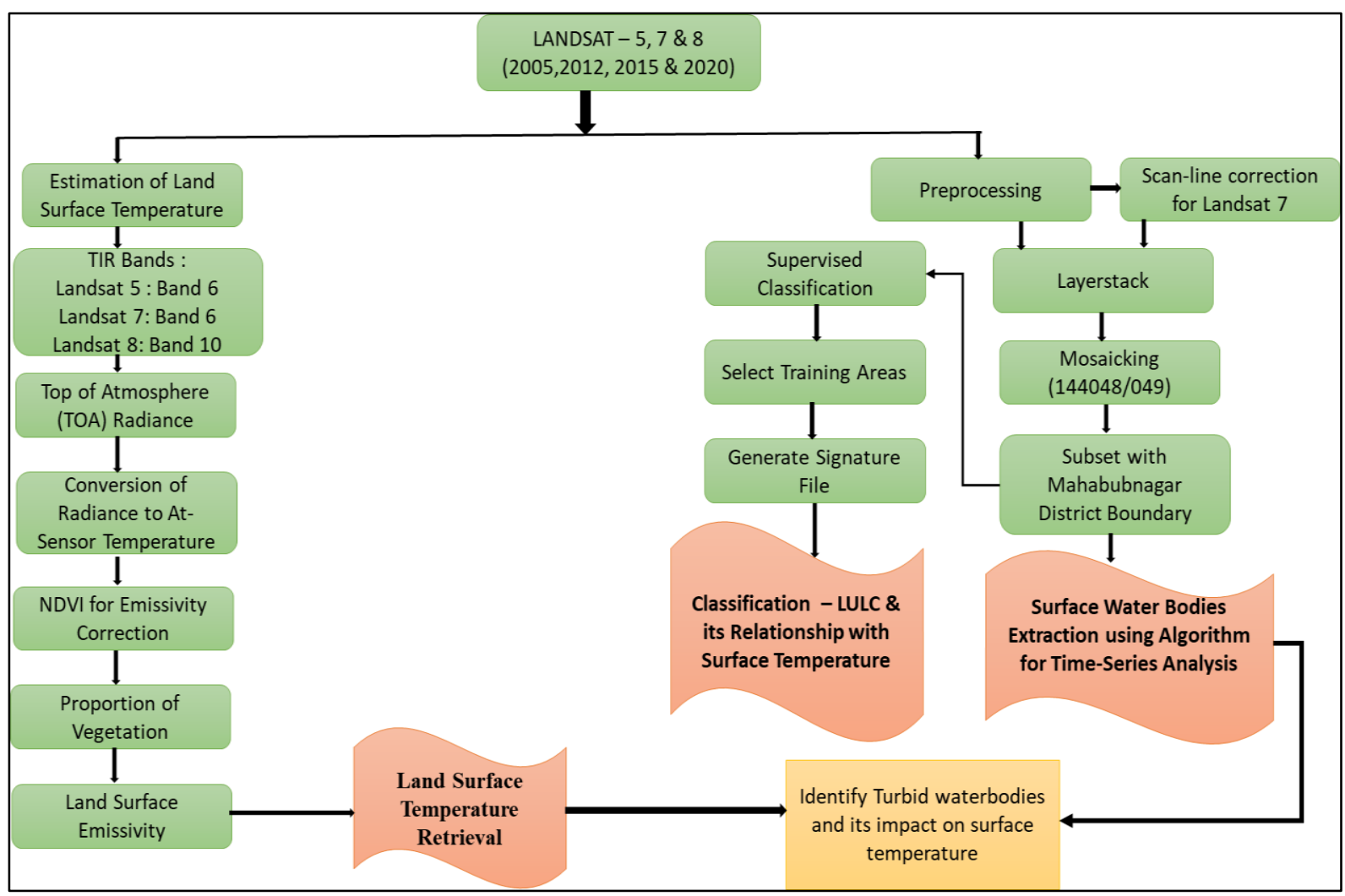

Figure 2. Flowchart for determining LST, LULC, and extraction of surface waterbodies

\subsubsection{Estimation of Land Surface Temperature}

The LST was estimated using the thermal infrared band of Landsat 8 OLI, Landsat 7 ETM+, and Landsat 5 TM, by following the image processing operations [16].

\section{Step 1: Top of Atmosphere (TOA) Radiance}

The digital number (DN) of the thermal band (Band 10 for Landsat 8, Band 6 for Landsat 5 and Landsat 7) is converted to TOA radiance using an algorithm that uses additive and rescaling factors allocated to specific bands, as indicated in the metadata to calculate the radiance value.

\section{For Landsat 8:}

$$
L \lambda=M L * Q \mathrm{cal}+A L-O i
$$

where:

$\mathrm{L} \lambda$ represents TOA radiance in watts/ $\left(\mathrm{m}^{2} * \mathrm{srad}^{*} \mu \mathrm{m}\right)$,

$M L$ represents the band-specific multiplicative rescaling factor (taken from metadata file),

$Q$ cal is the quantized calibrated pixel value in Band 10 image,

$A L$ is the band-specific additive rescaling factor (taken from metadata file), and $O i$ is the correction for Band 10, which is 0.29.

\section{While for Landsat 5 and 7:}

$$
\begin{gathered}
\mathrm{L} \lambda=(\mathrm{L} \lambda \max -\mathrm{L} \lambda \min / \text { Qcalmax }- \text { Qcalmin }) * \\
(\text { Qcal }- \text { Qcalmin })+\mathrm{L} \lambda \min
\end{gathered}
$$

where:

$\mathrm{L} \lambda$ represents TOA radiance in watts/ $\left(\mathrm{m} 2 * \operatorname{srad}^{*} \mu \mathrm{m}\right)$,

QCAL $-Q$ cal is the quantized calibrated pixel value in Band 6 image,

L $\lambda$ min - spectral radiance scales to QCALMIN (taken from Metadata file),

L $\lambda$ max - spectral radiance scales to QCALMAX (taken from metadata file),

QCALmin = minimum quantized pixel value (typically $=1$ ),

and QCALmax = maximum quantized pixel value (typically $=255$ ).

\section{Step 2: Radiance to At-Sensor Temperature Conversion}

The thermal infrared sensor (TIRS) band data should be converted from spectral radiance to brightness temperature (BT), using the thermal constants provided in the metadata file once the DNs have been translated to reflection. To convert reflectance to BT, use the following equation: Table 2 shows the metadata value for the band specifics. 
Table 2. Metadata for Landsat 5,7 \& 8:

\begin{tabular}{|c|c|c|c|c|c|}
\hline Sensor & K1 & K2 & $\begin{array}{c}\text { Rescaling Factor } \\
\text { (ML) }\end{array}$ & $\begin{array}{c}\text { Rescaling Factor } \\
\text { (AL) }\end{array}$ & Correction (Oi) \\
\hline Landsat 8 OLI - (Band 10) & 1321.08 & 777.89 & 0.000342 & 0.1 & 0.29 \\
\hline Landsat 7 ETM+ (Band 6) & 666.09 & 1282.71 & - & - & - \\
\hline Landsat 5 TM (Band 6) & 607.76 & 1260.56 & - & - & - \\
\hline
\end{tabular}

\section{For Landsat 5, 7 and 8:}

$$
\mathrm{BT}=(\mathrm{K} 2 / \mathrm{In}(\mathrm{K} 1 / L \lambda+1))-273.15
$$

where:

$K 1$ and $K 2$ stand for the band-specific thermal conversion constants from the metadata.

For obtaining the results in Celsius, the radiant temperature is revised by adding the absolute zero (approx. $\left.273.15^{\circ} \mathrm{C}\right)$.

Step 3: NDVI Method for Emissivity Correction

NDVI Calculation: The NDVI was calculated using the visible and NIR bands of the Landsat dataset. NDVI is an essential parameter since it is used to compute the proportion of vegetation $(\mathrm{Pv})$, which is connected to NDVI and emissivity $(\varepsilon)$. The NDVI is calculated as follows:

$$
\mathrm{NDVI}=(\mathrm{NIR}-\mathrm{Red}) /(\mathrm{NIR}+\mathrm{Red})
$$

Proportion of Vegetation (Pv) Calculation: Proportional vegetation cover is calculated using the NDVI values using the algorithm shown below:

$$
\mathrm{Pv}=((\text { NDVI }- \text { NDVIs }) /(\text { NDVIv }- \text { NDVIs }))^{2}
$$

where:

NDVIv \& NDVIs represents NDVI value for vegetation and soil.

\section{Step 4: Land Surface Emissivity (LSE)}

The emissivity of any object can be defined as its ability to measure the emitted infrared energy required to convert BT readings to surface temperature, as shown in the following algorithm:

$$
\mathrm{LSE}=\varepsilon S(1-\mathrm{FVC})+\varepsilon V
$$

where:

$\varepsilon V$ represents emissivity of vegetation,

ES represents emissivity of soil,

and $\mathrm{Pv}(\mathrm{FVC})$ represents proportional vegetation cover.

Step 5: Land Surface Temperature

The LST is the relative temperature determined using the following algorithm: BT, wavelength of emitted radiance and LSE.

$$
\mathrm{LST}=\mathrm{BT} /(1+(\lambda * \mathrm{BT} / \mathrm{C} 2) * \mathrm{In}(\mathrm{LSE}))
$$

where:

BT represents TOA brightness temperature (degree Celsius),

$\lambda$ represents wavelength of emitted radiance (for Band 10 , it is taken as 10.8),

LSE represents land surface emissivity (from previous step calculation),

$$
\mathrm{C} 2=\mathrm{h} * \mathrm{c} / \sigma=1.438 \times 10^{-2} \mathrm{mK} \text {, }
$$

where $\sigma$ is the Boltzmann constant $\left(1.38 \times 10^{23} \mathrm{~J} / \mathrm{K}\right), h$ is Planck's constant $\left(6.626 \times 10^{-34} \mathrm{~J} \mathrm{~s}\right)$, and $c$ is the velocity of light $\left(2.998 \times 10^{8} \mathrm{~m} / \mathrm{s}\right)$.

Figure $3 \& 4$, depicts the LST derived from above mentioned steps for the study areas. 


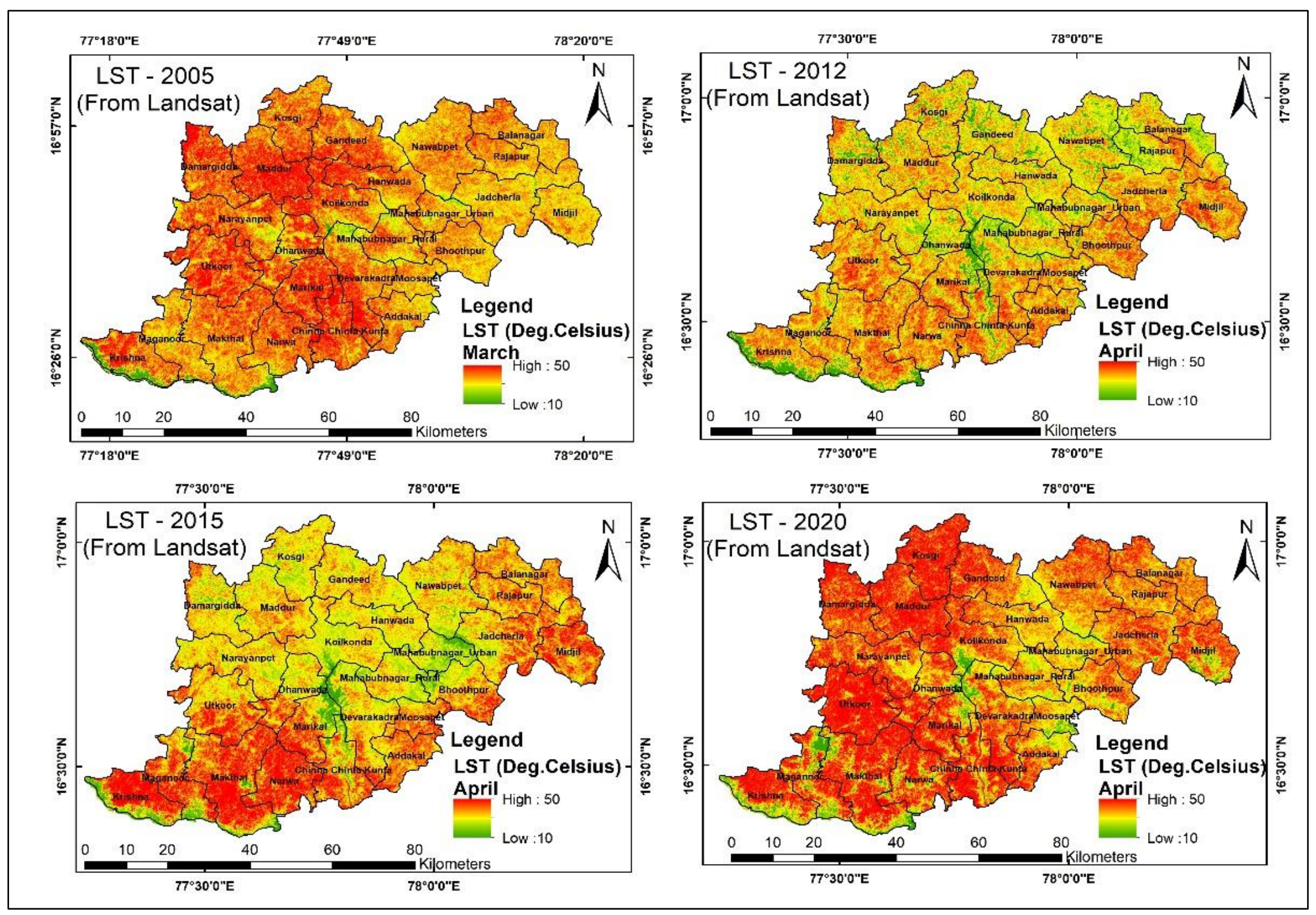

Figure 3. Estimated Land Surface Temperature (a) March 2005 (b) April 2012 (c) April 2015 and (d) April 2020: Pre-Monsoon 


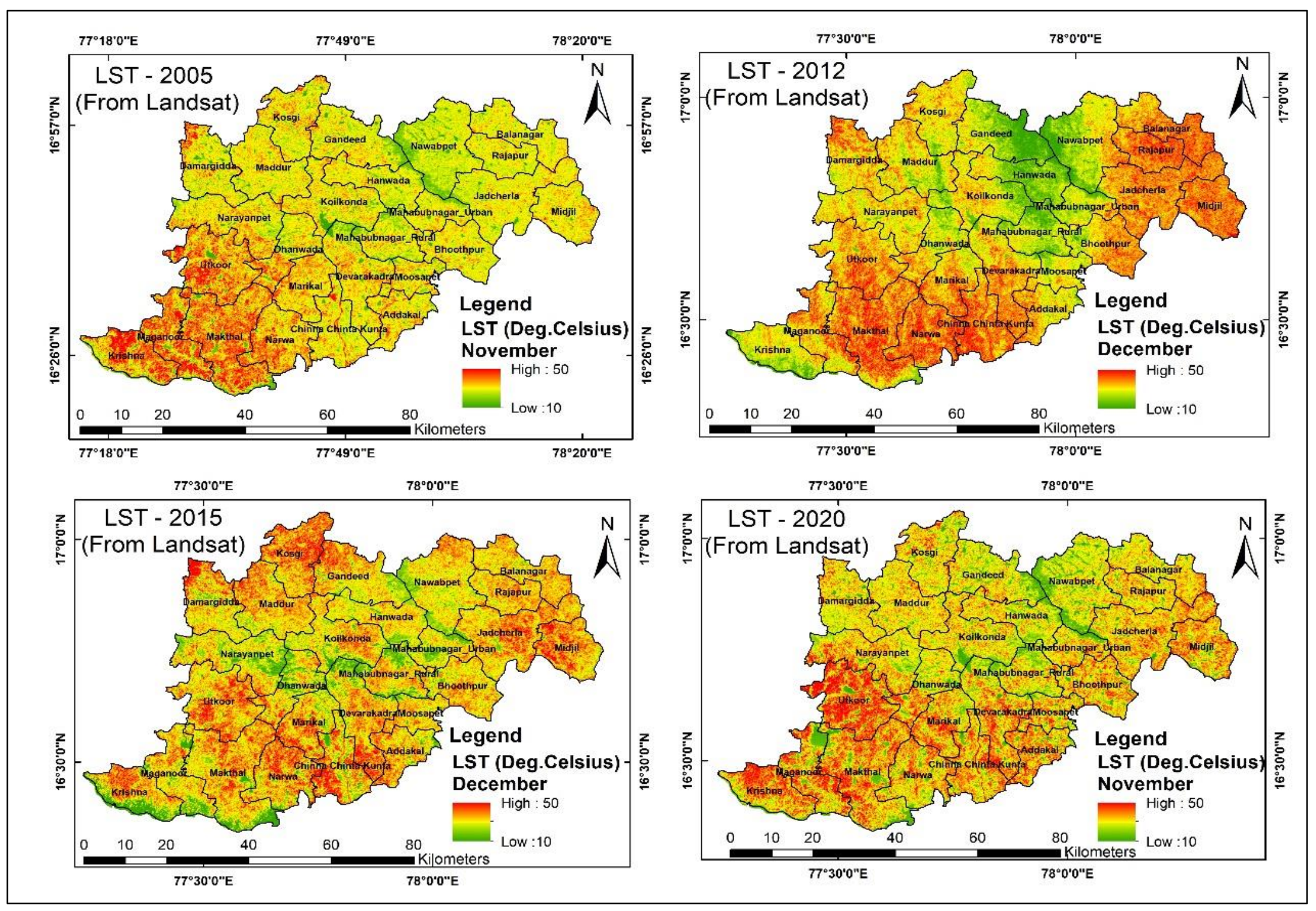

Figure 4. Estimated Land Surface Temperature (a) November 2005 (b) December 2012 (c) December 2015 and (d) November 2020: Post-Monsoon 


\subsubsection{Validation of derived LST using MODIS Data in Google Earth Engine}

The validation of LST values in this study was done using MODIS datasets. For the years 2005, 2012, 2015, and 2020 MOD11A1 (1 km spatial resolution) was utilized for Pre-Monsoon and Post-Monsoon. The derived LST using Landsat was found to be co-related with MODIS LST values after estimating the LST in Google Earth Engine (Figure 5 and Figure 6).

Temperature was high for the month of April 2020 in both cases of LST derived from Landsat and MODIS data. In the year 2020, the majority of the Tehsils in the district had high temperature (Pre-Monsoon). The rise in temperature in recent years could be attributed to a lack of rainfall and an increase in built-up.

However, due to the lack of rainfall in the year 2014-2015, majority of the tehsils recorded higher temperature in December 2015 from both Landsat and MODIS derived LST. (Figure $4 c \& 6 c$ ). This was linked to seasonal precipitation from June to September 2015, which showed Moderate drought, Mild drought, and Normal conditions (Figure 10) for the southern part of the district.

\subsubsection{Land Use and Land Cover Classification}

For the years 2005 and 2020, Landsat 5 (TM) and Landsat 8 (OLI) were utilized to create LULC maps
(Figure 7). Supervised LULC classification was done in Google Earth Engine and by visual interpretation technique and assigning signature classes for each feature. The steps followed for Supervised Classification in GEE are:

1. Create the training datasets for each feature. Assemble features with a property that stores the known class name and properties that store the predictors' numeric values:

- Hover over the 'Geometry Imports' box next to the geometry drawing tools and click 'Add new layer' using the visual interpretation as a guide. Each additional layer in the training data represents a different class.

2. Train the classifier (viz. random forest, SmileCART):

- Use ee.Classifier.randomForest() or ee.Classifier.SmileCART() to create a classifier and train it on the training data, selecting the features to utilize (training) and the landcover categories as the class.

3. Classify the image and sort them into groups:

- At this stage features showing similar textures, patterns were categorized into one group. The groups were waterbodies, vegetation, built-up, fallow and dried river networks. 


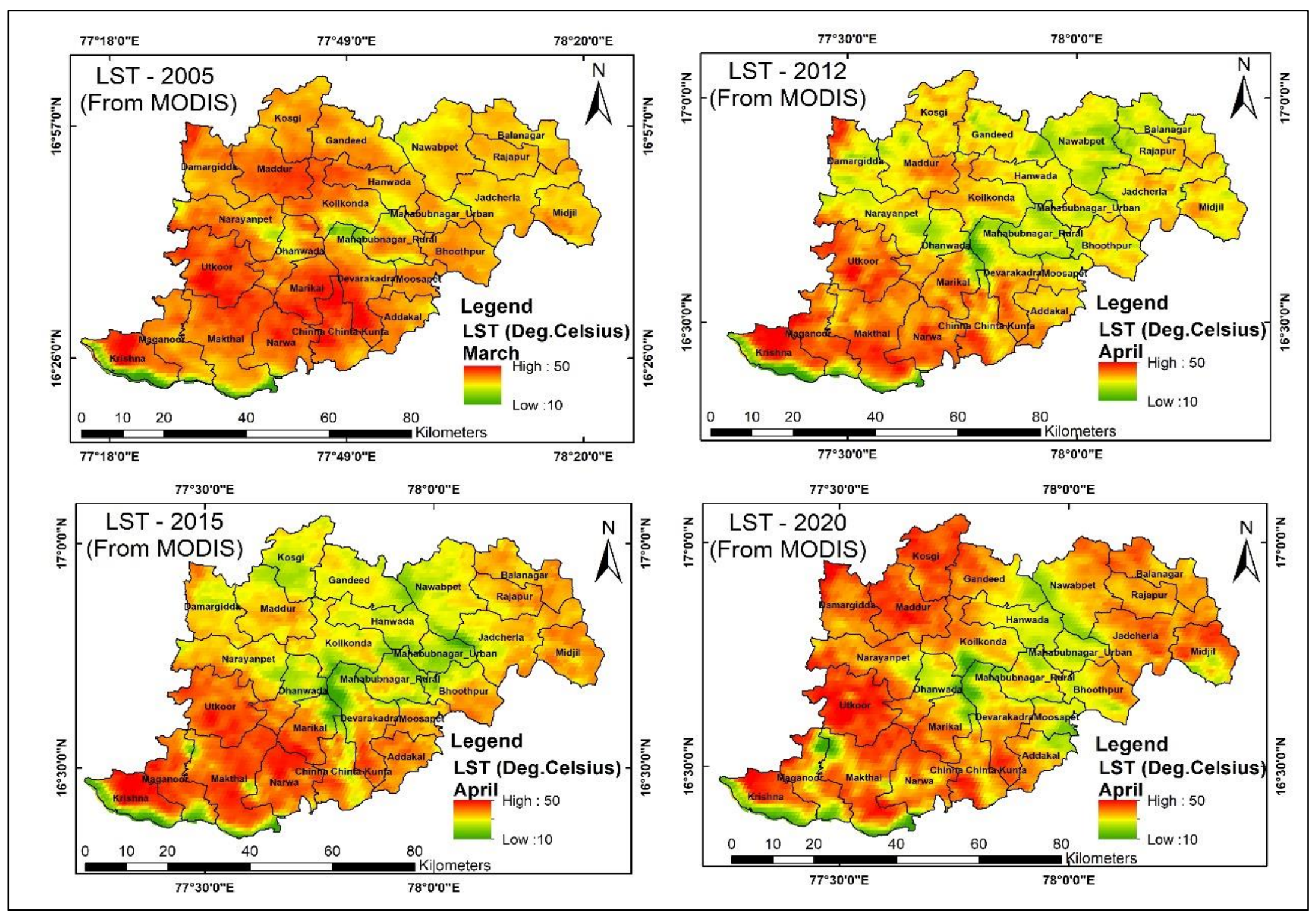

Figure 5. Estimated Land Surface Temperature (a) March 2005 (b) April 2012 (c) April 2015 and (d) April 2020: Pre-Monsoon 


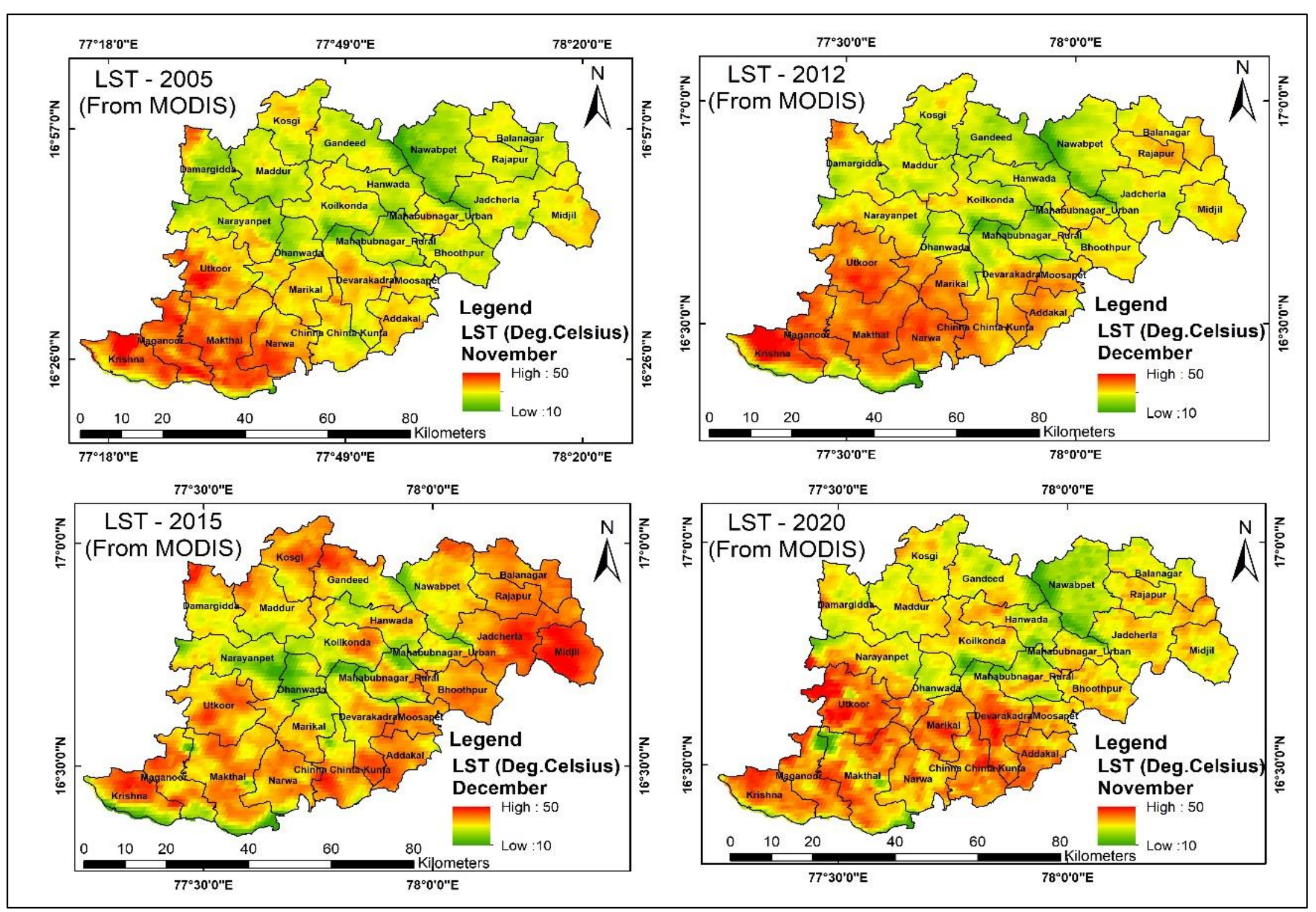

Figure 6. Estimated Land Surface Temperature (a) November 2005 (b) December 2012 (c) December 2015 and (d) November 2020: Post-Monsoon 


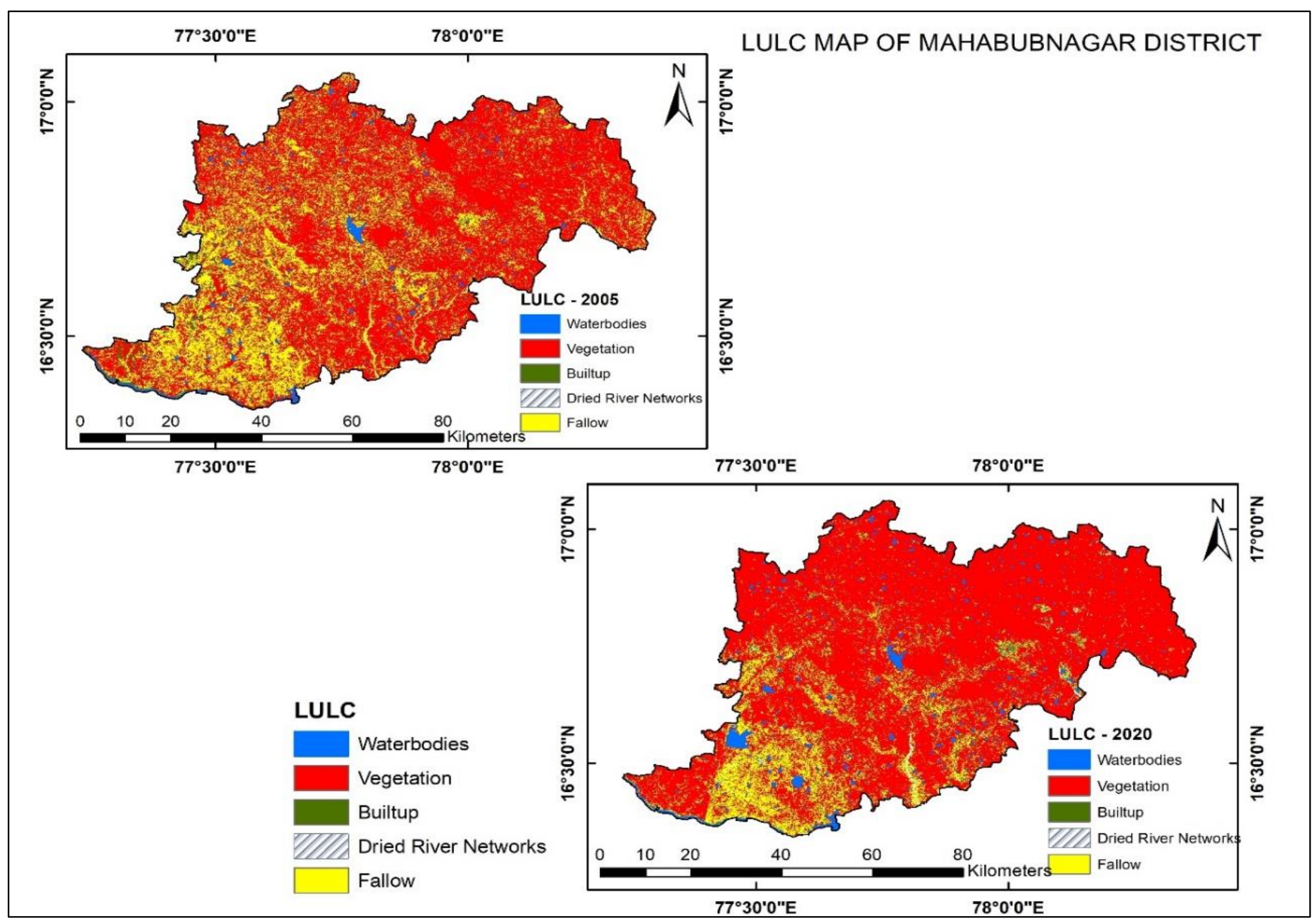

Figure 7. LULC Map of Mahabubnagar District: 2005 \& 2020 


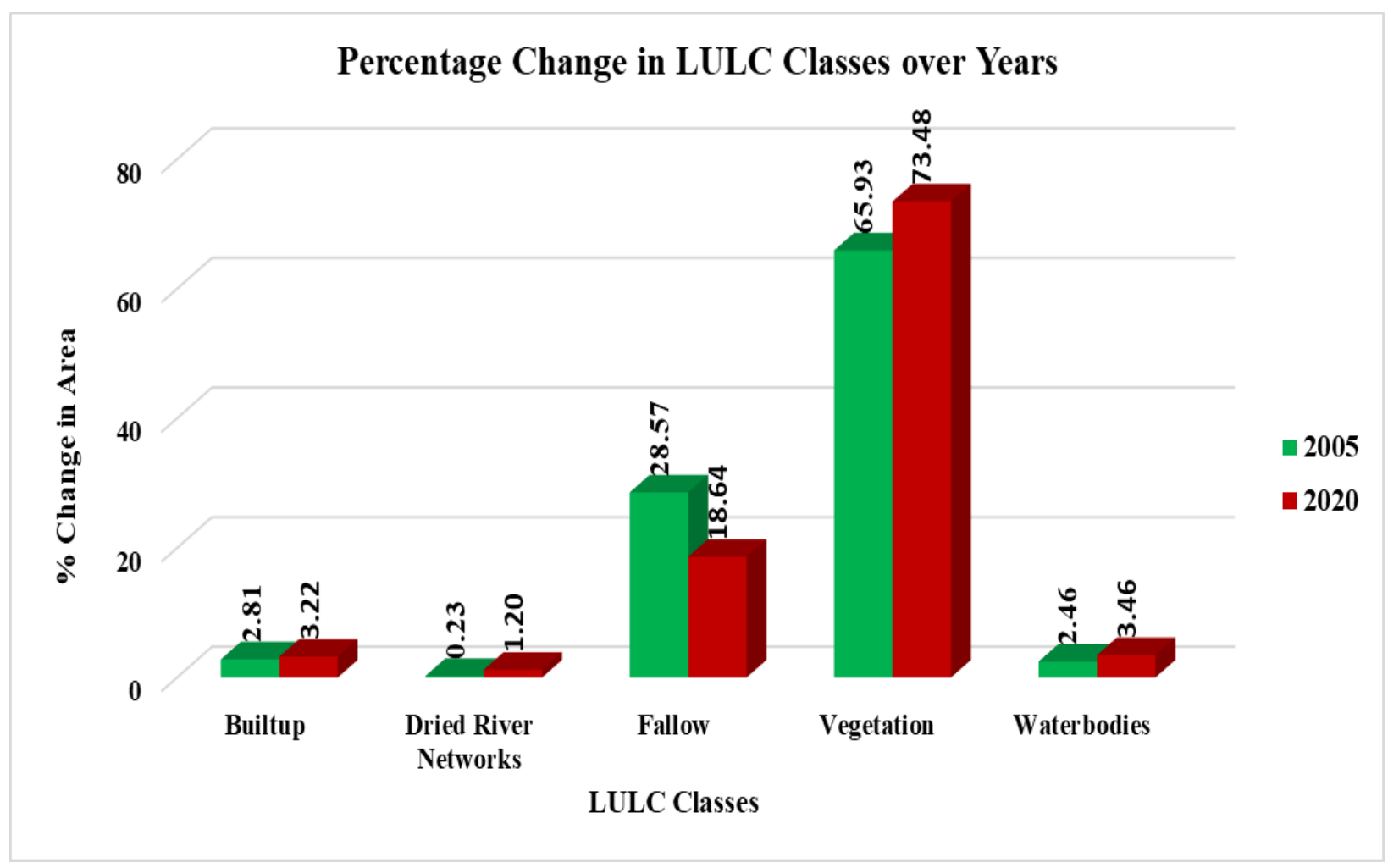

Figure 8. LULC \% Change in area for 2005 and 2020 for Mahabubnagar District

Table 3 shows the results of the change detection analysis for each class. The percentage change in various LULC classes was calculated to determine the change that occurred over time (Figure 8).

Table 3. Changes in different LULC Classes 2005 and 2020

\begin{tabular}{|c|c|c|}
\hline Classes & $\begin{array}{c}\text { Percentage } \\
\mathbf{2 0 0 5}\end{array}$ & Percentage 2020 \\
\hline Built-up & 2.81 & 3.22 \\
\hline Dried River Networks & 0.23 & 1.20 \\
\hline Fallow & 28.57 & 18.64 \\
\hline Vegetation & 65.93 & 73.48 \\
\hline Waterbodies & 2.46 & 3.46 \\
\hline
\end{tabular}

The above data show that built-up increased from 2005 to 2020. Both vegetation and waterbodies rose from 2005 to 2020 , indicating a promising future. The increase in vegetative areas is proportional to the increase in surface temperature in inverse proportion.

\subsubsection{Relationship between LULC and LST}

A trial was conducted to determine the link between LST and LULC (various types of characteristics). Different features/classes respond to LST in different ways. This is because the topographic parameter of an urban region affects the spatial properties of the land surface [17].

Changes in LULC have a great impact on eco-systems globally [18] which includes both environment and central / state planning [19]. The LST has an inverse relationship with green cover, and vegetation can significantly reduce LST in urban areas, making cities less vulnerable to climate change [20].

Figure 9 depicts the change in mean LST in Mahabubnagar District from 2005 to 2020. For the years 2005, 2016, 2017, and 2019, the mean land surface temperature was above 40 degrees Celsius.

According to a report published at https://sandrp.in/2016/05/18/telangana-drought-2016/ [21], the year 2015 was deemed a drought year due to a lack of rainfall throughout Telangana, which also affected Mahabubnagar District.

Seasonal Rainfall (June to September) was examined in GEE for the years 2014 and 2015, and the results are given in Figure 10. It has been divided into three categories: Moderate Drought (shown in orange), Mild Drought (shown in yellow), and Normal (shown in green). The influence of the dry spell has been apparent in LST estimates, with the majority of tehsils reporting higher temperatures in December 2015 (figure 4c \& 6c). 


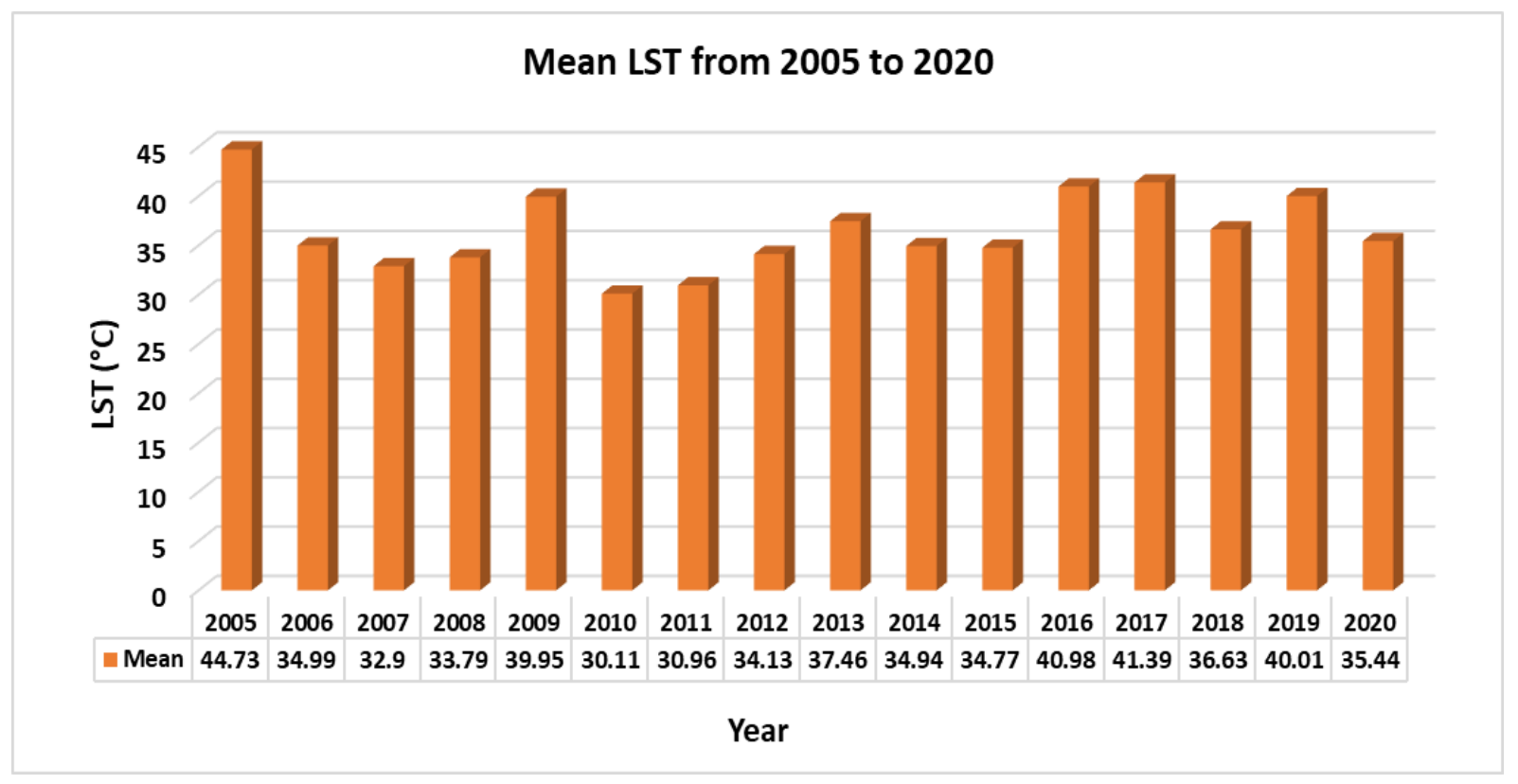

Figure 9. Mean LST of Mahabubnagar District from 2005 to 2020 (April)

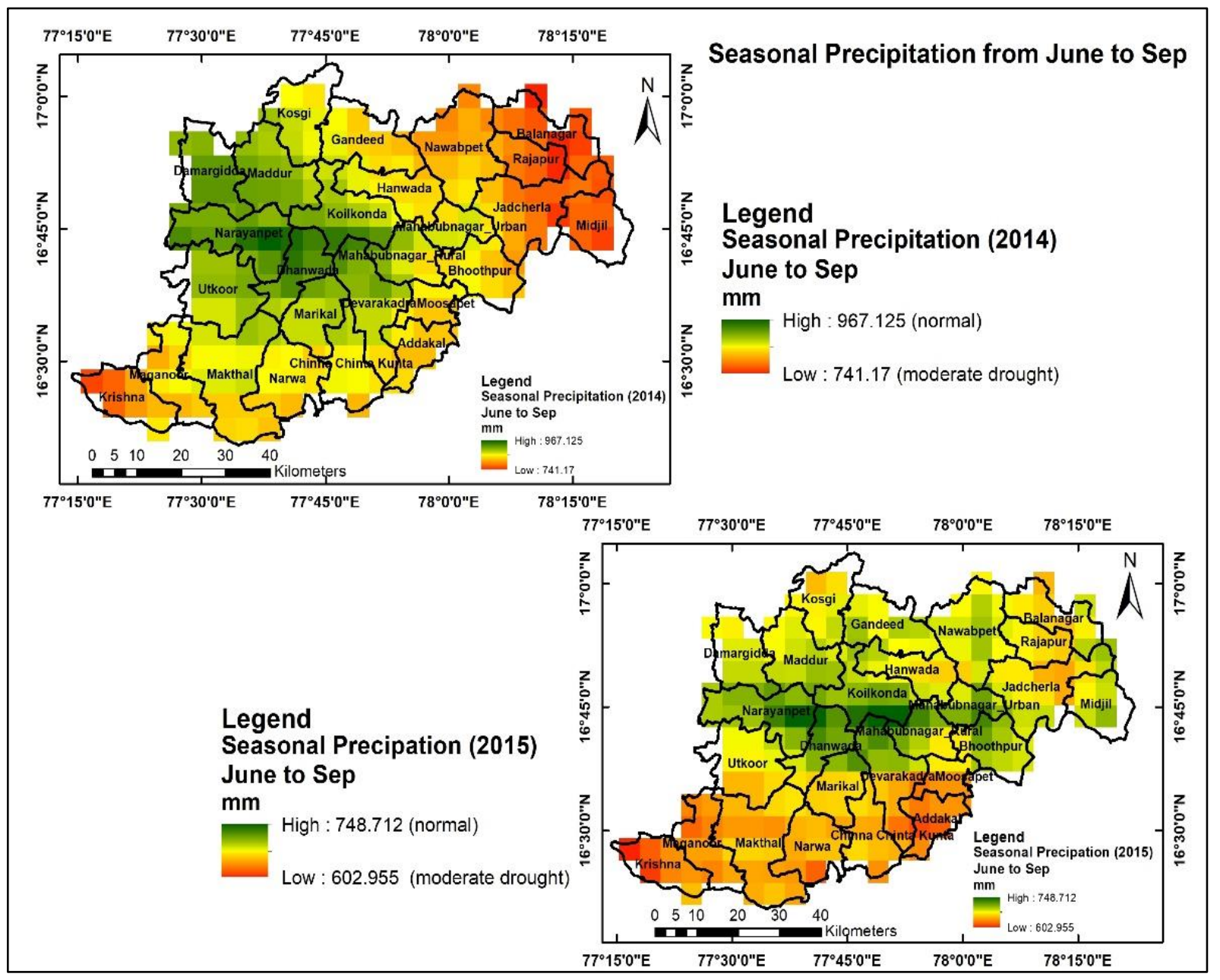

Figure 10. Seasonal Precipitation from June to Sep for 2014 \& 2015 


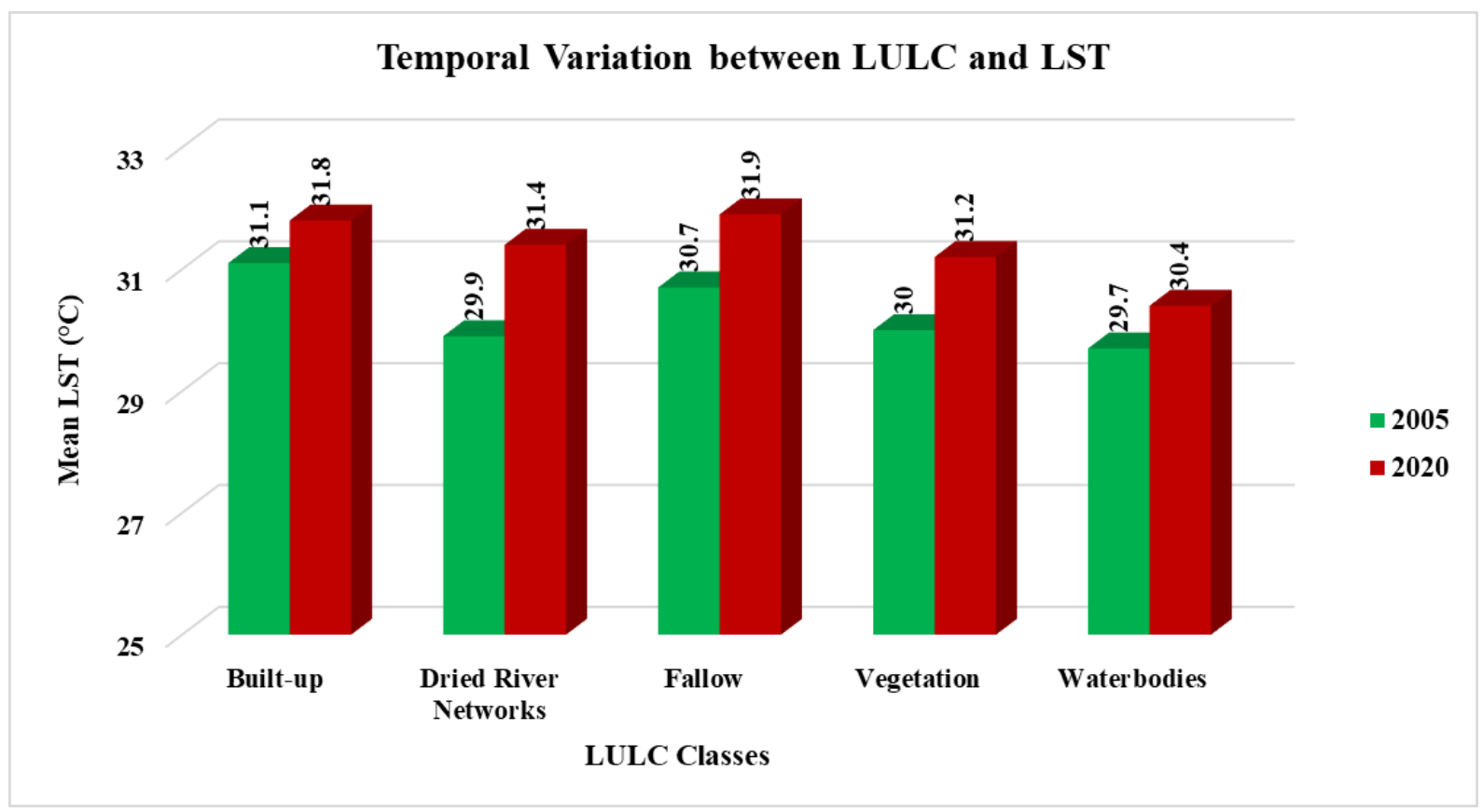

Figure 11. Temporal Variations between LULC and LST

The LULC study reveals a consistent shift in temperature from 2005 to 2020 for various land features (Figure 11). The local climate has also been influenced by these land-use changes. The change in LST is proportional to the pace of change in urbanization. The use of change detection techniques to create altered patches and change attributes from multi-resolution satellite pictures is both desirable and hard. The rise in temperature from 2005 to 2020 for various land features is approx. $2^{\circ} \mathrm{C}$.

\subsubsection{Extraction of Surface Waterbodies to determine time-series change of Water Spread Area}

Long-term surface water extent and occurrence were taken from the Landsat series Global Surface Water (1984-2020) [22]. Between 1984 and 2020, the Water
Occurrence map indicates where surface water occurred and gives information on general water dynamics. Over a 37-year span, the Maximum Water Extent gives information on all the areas that have ever been detected as water. The Maximum Water Extent and Occurrence layer were extracted in Google Earth Engine (Figure 12).

The Koil Sagar Reservoir and the Jurala Reservoir both have permanent water (i.e. $100 \%$ occurrence), whereas the other waterbodies had seasonal water (indicated in pink shade in the Figure 12). Seasonal water can be found in Mahabubnagar Old Lake, Bhoothpur Dam, and other water sources.

To determine changes in the Water Spread Area (WSA) over time, the maximum water extent layers were used as the reference layer. 


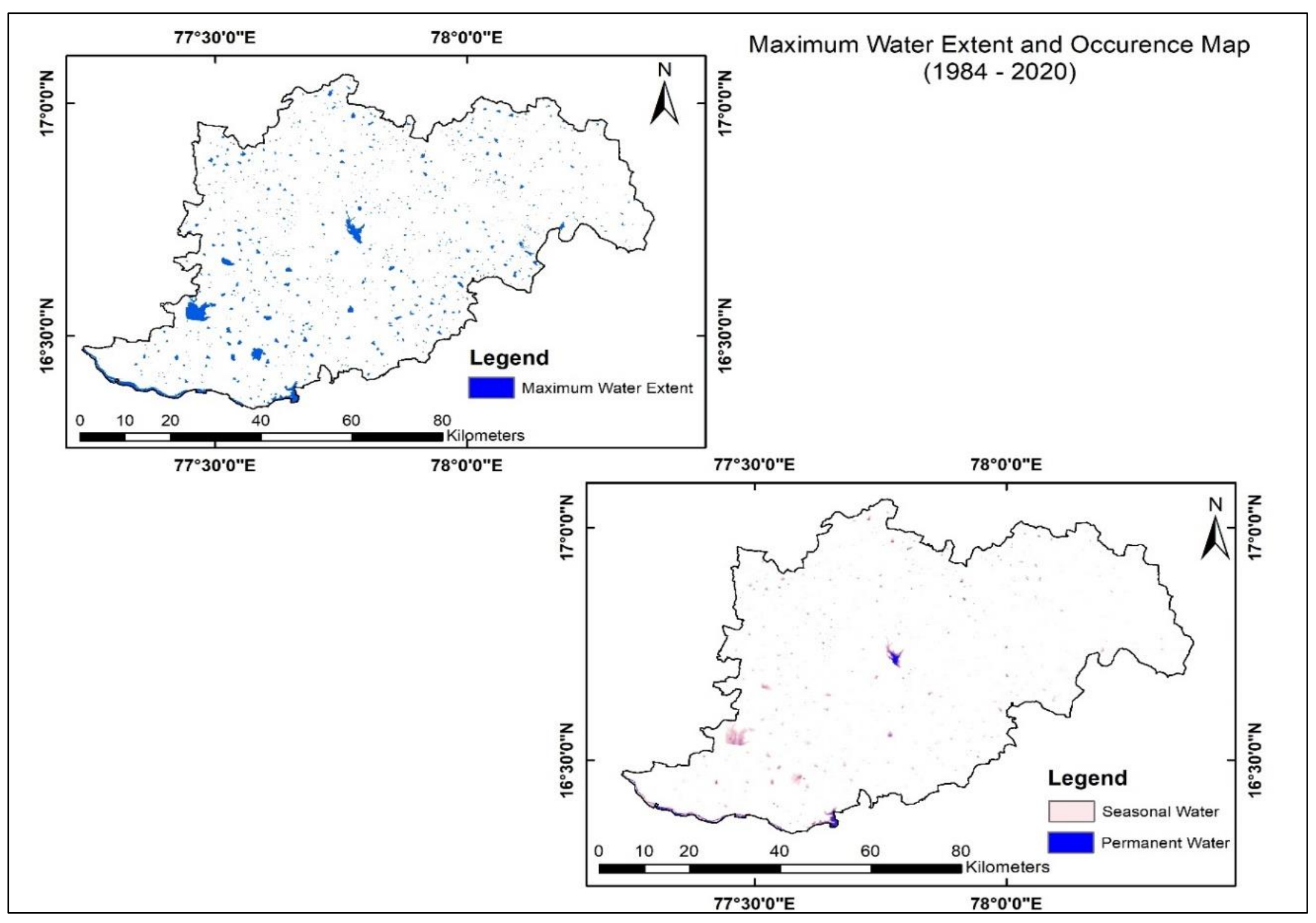

Figure 12. Maximum Water Extent and Occurrence Map of the Study Area 


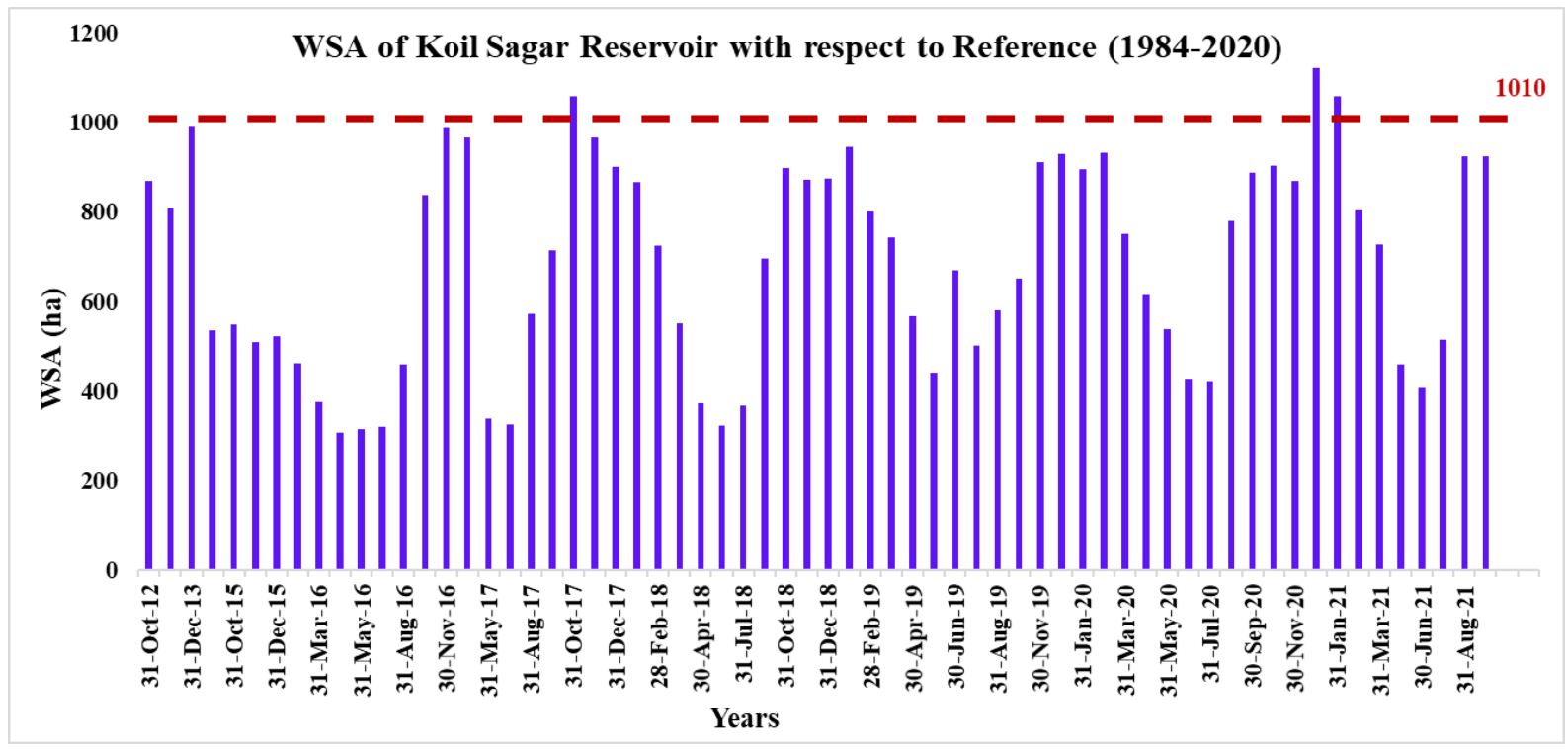

WSA of Bhoothpur Dam with respect to Reference (1984-2020)

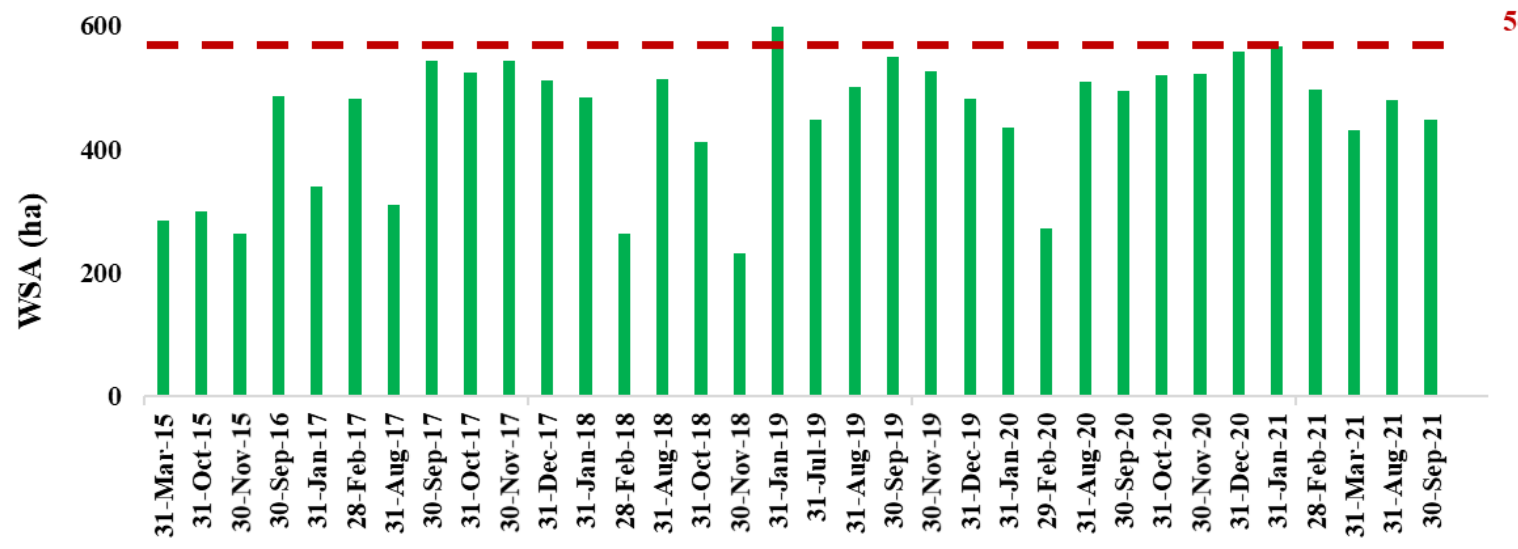

Years

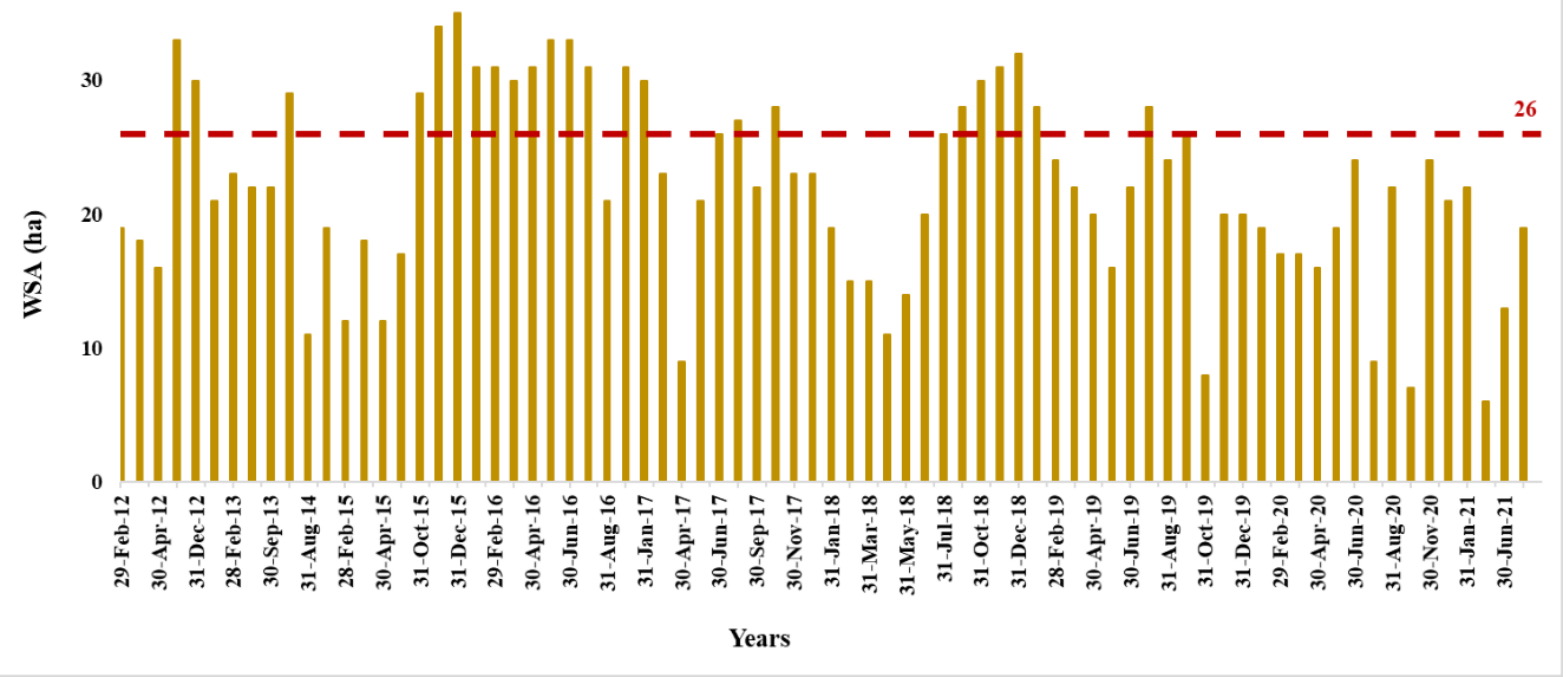

Figure 13. WSA of major waterbodies of Mahabubanagar District with respect to Reference (1984-2020) 


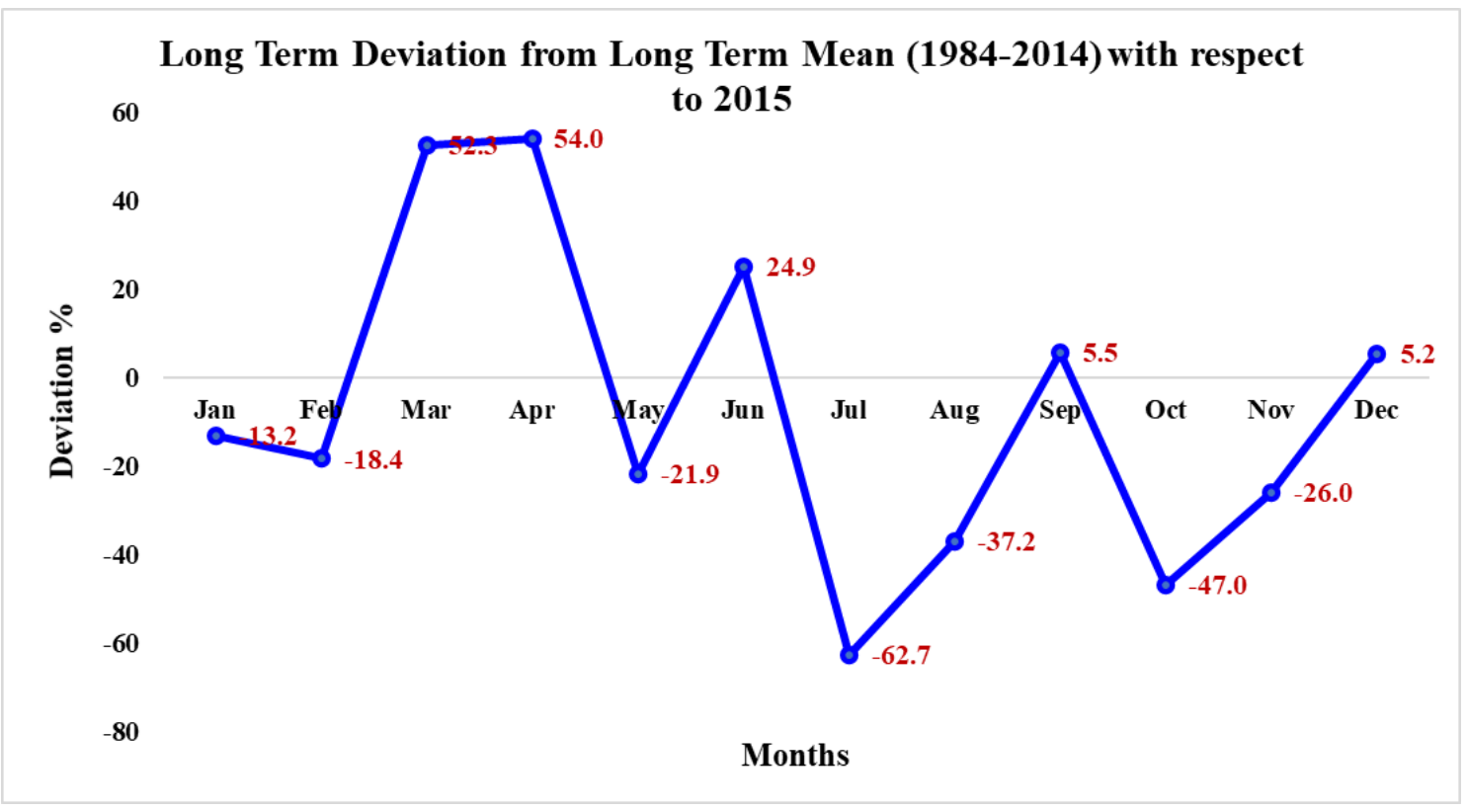

Figure 14. Monthly Rainfall Deviation from Long Term Mean (1984-2014) of the study area

The reference Water Spread Area (WSA) indicated in red dotted line on the above graphs (Figure 13) was acquired from Global Surface Water Layer, Maximum Extent (1984-2020). Since 2012, the WSA extracted has been computed using a developed algorithm and several indexes, and it has been uploaded to the NRSC's WBIS BHUVAN portal at biweekly and monthly intervals. Spectral characteristics of water pixels are analysed and sensor specific automated water bodies extraction algorithms are developed at NRSC /ISRO and being utilized for quick processing of multi-sensor satellite data that is acquired on daily basis as per the satellite coverage of individual satellites / sensors.

\subsubsection{Long Term Rainfall using CHIRPS PENTAD Data}

CHIRPS (Climate Hazards Group InfraRed Precipitation with Station Data) is a 40-year quasi-global rainfall dataset (1981-2021). For trend analysis and seasonal drought monitoring, CHIRPS builds gridded rainfall time series using $0.05^{\circ}$ resolution satellite imagery and in-situ station data [23].

The percentage of monthly rainfall deviation was estimated using CHIRPS PENTAD data in GEE from 1984 to 2014 with respect to 2015 (Figure 14), as 2015 was declared a dry year. As a result, a rainfall graph was created to verify this, and it was observed that the majority of the months had insufficient rainfall. As a result of the lack of rainfall, the surface temperature was affected as well, as stated in the previous section.

\section{Results and Discussions}

For both Pre-Monsoon and Post-Monsoon, LST was computed using Landsat series for the years 2005, 2012,
2015, and 2020. Because 2015 was considered a drought year, temperatures were higher in some parts of the district in December 2015, and rainfall was even lower. This was validated using CHIRPS PENTAD Rainfall data from 1984 to 2014 with respect to 2015 , which indicated a negative percentage of deviation for practically every month.

For the years 2005 and 2020, LULC was categorized, and the percentage change in various land cover was examined. The percentage of built-up area was $2.81 \%$ in 2005, but it went to $3.22 \%$ in 2020. Near Mahabubnagar Old Lake, the growth in built-up areas was most noticeable. From 2005 to 2020 , vegetation increased from $65.93 \%$ to $73.48 \%$. Increased vegetation is a good sign because it will help to keep the temperature rise under control for years to come.

Seasonal Precipitation (June to September) was evaluated in GEE for the years 2014 and 2015, and it showed that a few tehsils in the district had experienced moderate drought. The mean LST for various land cover classes was estimated, and it exhibited approx. $2^{\circ} \mathrm{C}$ increase in temperature in 2020 as compared to 2005.

Global Surface Water (1984-2020) in GEE was used to obtain the maximum water extent and occurrence. Permanent water was found in the Koil Sagar Reservoir and the Jurala Reservoir, whereas the majority of the waterbodies are seasonal and newly formed. The maximum extent is used as a reference to evaluate the temporal changes in water spread area (WSA) from 2012 to September 2021. At NRSC, an algorithm for automatic extraction of surface water bodies was established, and it is published on the NRSC's WBIS Portal at fortnightly and monthly intervals. This provides real-time data on surface waterbodies, which can be utilized for irrigation, agriculture, and drinking. This fortnightly and monthly 
data can aid in judicious water usage planning.

Finally, the NDWI and LST were compared, and it was observed that turbid water has a higher temperature than clear water. Turbidity is caused by particles suspended or dissolved in water resulting in cloudy or murky water.
Hence, temperature will be more in turbid water. In the near infrared wavelength range, pure water has a high absorption and no reflectance, whereas turbid water has a larger reflectance in the visible region than clear water (Figure 15 \& 16).

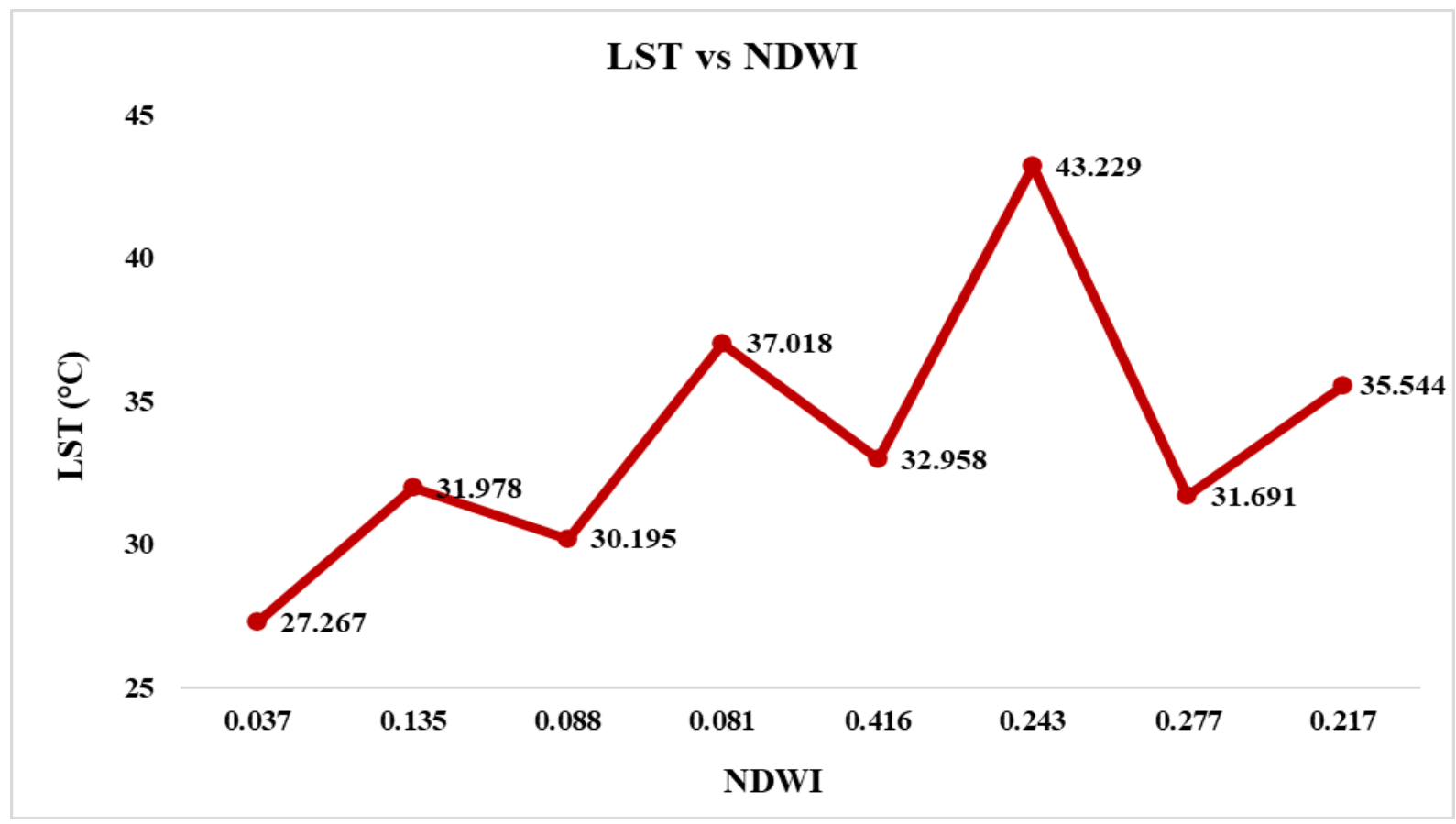

Figure 15. Relationship between NDWI \& LST
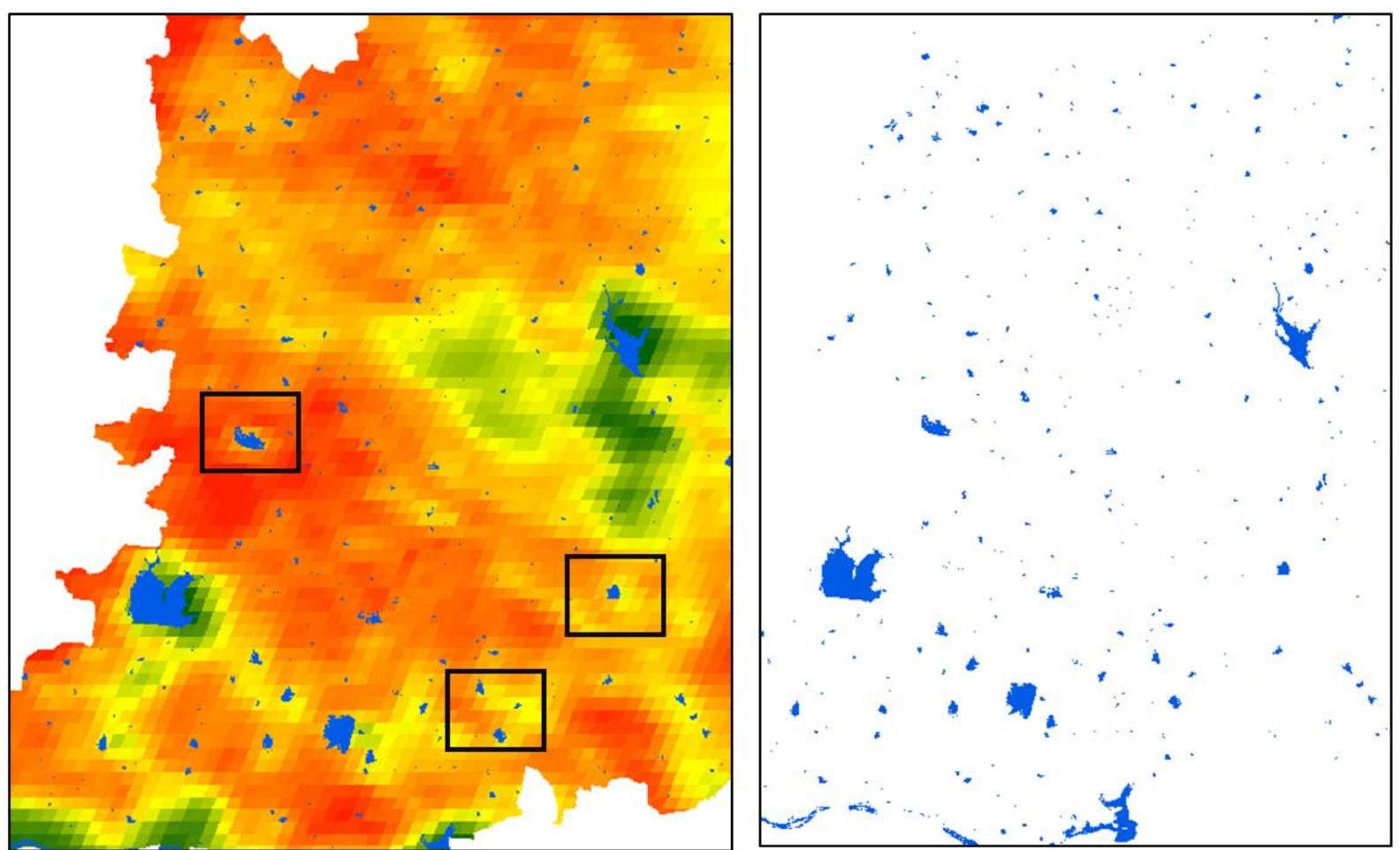

Figure 16. Waterbodies extracted using NDWI (R) and LST and NDWI of the study area (L) 


\section{Conclusions}

In this study, remote sensing and GIS were combined to analyze and explain LST changes in Telangana's Mahabubnagar District over a 15-year period, from 2005 to 2020. The LST was computed using Landsat Thermal Band data and validated using MODIS data. The LULC was estimated with the help of multi-temporal satellite data, and the impact of LST on land cover features was examined. A rise in temperature was found in the land cover features from 2005 to 2020 . Turbid waterbodies have a higher temperature than pure waterbodies. Waterbodies should not be polluted since it will render the water dirty, making it unfit for drinking, agriculture, or irrigation, and it will also cause an increase in temperature.

Because 2015 was designated as a drought year, a long-term rainfall study from 1984 to 2014 was done with respect to 2015. The majority of the months had negative deviation as rainfall was limited that year.

However, for the environment's long-term sustainability, excessive temperature rises should be continuously monitored and mitigated in the future by planting trees on both sides of the road.

\section{REFERENCES}

[1] Idowu T E Kiplangat N C and Waswa R (2019). Land cover changes and its Implications on Urban Heat Island in Nairobi County: A GIS and Remote Sensing Approach.

[2] McGrane S J (2016). Impacts of urbanisation on hydrological and water quality dynamics and urban water management: a review Hydrological Sciences Journal 61(13) 2295-2311.

[3] Wan, Z., Zhang, Y., Zhang, Q., \& Li, Z.-L. (2004). Quality assessment and validation of the MODIS global land surface temperature. International Journal of Remote Sensing, 25, 261-274.

[4] https://ourworldindata.org/urbanization

[5] Tanushri Jaiswal and D C Jhariya (2020). Monitoring the Land Surface and water bodies temperature and its impact on surface water turbidity in Raipur, Chhattisgarh, India. IOP Conf. Ser.: Earth Environ. Sci. 597012008.

[6] Kaicun Wang and Shunlin Liang (2009). Evaluation of ASTER and MODIS land surface temperature and emissivity products using long-term surface longwave radiation observations at SURFRAD sites. Remote Sensing of Environment 113 (2009) 1556-1565.

[7] Mas, J.-F. Monitoring land-cover changes (1999). A comparison of change detection techniques. Int. J. Remote Sens. 20, 139-152.

[8] Omar, P.J; Gupta, N; Tripathi, R.P; Shekhar, S.S (2017). A study of change in agricultural and forest land in Gwalior city using satellite imagery. S-JPSET - 9, 109-112.

[9] Prakasam, C. (2010). Land use and land cover change detection through remote sensing approach: A case study of Kodaikanal taluk Tamilnadu. International Journal of Geomatics and Geosciences.1, (2), 150-158.

[10] Reis, S. (2008). Analyzing land use/land cover changes using remote sensing and GIS in Rize, North-East Turkey. Sensors, 8(10), 6188-6202.

[11] R. Douglas Ramsey, Dennis L. Wright Jr. \& Chris McGinty (2004) Evaluating the Use of Landsat 30m Enhanced Thematic Mapper to Monitor Vegetation Cover in Shrub Steppe Environments, Geocarto International, 19:2, 39-47, DOI: $10.1080 / 10106040408542305$.

[12] S. K. McFeeters (1996) The use of the Normalized Difference Water Index (NDWI) in the delineation of open water features, International Journal of Remote Sensing, 17:7, 1425-1432, DOI: 10.1080/01431169608948714.

[13] Hanqiu Xu (2006). Modification of normalised difference water index (NDWI) to enhance open water features in remotely sensed imagery. International Journal of Remote Sensing Vol. 27, No. 14, 20 July 2006, 3025-3033.

[14] Lei Ji, Li Zhang and Bruce K. Wylie (2009). Analysis of Dynamic Thresholds for the Normalized Difference Water Index. Article in Photogrammetric Engineering and Remote Sensing · November 2009. DOI: 10.14358/PERS.75.11.13 07

[15] Feyisa, G.L.; Meilby, H.; Fensholt, R.; Proud, S.R (2014). Automated water extraction index: A new technique for surface water mapping using Landsat imagery. Remote Sens. Environ. 140, 23-35.

[16] Suresh. S., Ajay Suresh. V, Mani. K (2016). Estimation Of Land Surface Temperature of High Range Mountain Landscape of Devikulam Taluk Using Landsat 8 Data. IJRET: International Journal of Research in Engineering and Technology eISSN: 2319-1163, pISSN: 2321-7308.

[17] Voogt, J.A., 2004. Urban Heat Island: Hotter Cities. ActionBioscience, North Port, FL, USA. Available online: http://www.actionbioscience.org/environment/voogt.html.

[18] Sahana, M., Ahmed, R., \& Sajjad, H. (2016). Analyzing land surface temperature distribution in response to land use/ land cover change using split window algorithm and spectral radiance model in Sundarban Biosphere Reserve, India. Modeling Earth Systems and Environment, 2(2), 81. https://doi.org/10.1007/s40808-016-0135-5.

[19] Sinha, P., Kumar, L., \& Reid, N. (2012). Three-date landsat thematic mapper composite in seasonal land-cover change identification in a mid-latitudinal region of diverse climate and land use. Journal of Applied Remote, 6(1), 063595. https://doi.org/10.1117/1.JRS.6. 063595.

[20] Choudhury, D., Das, K., \& Das, A. (2018). Assessment of land use land cover changes and its impact on variations of land surface temperature in Asansol-Durgapur development region. Egypt Journal of Remote Sensing and Space Science, 22(2), 203-218 https://doi.org/10.1016/j. ejrs.2018.05.004.

[21] https://sandrp.in/2016/05/18/telangana-drought-2016/

[22] Jean-Francois Pekel, Andrew Cottam, Noel Gorelick, Alan S. Belward, High-resolution mapping of global surface water and its long-term changes. Nature 540, 418-422 (2016). (doi:10.1038/nature20584). 'Source: EC JRC/Google' 
[23] Funk, Chris, Pete Peterson, Martin Landsfeld, Diego Pedreros, James Verdin, Shraddhanand Shukla, Gregory Husak, James Rowland, Laura Harrison, Andrew Hoell \& Joel Michaelsen. "The climate hazards infrared precipitation with stations - a new environmental record for monitoring extremes". Scientific Data 2, 150066. doi:10.1038/sdata.2015.66 2015. 